\title{
Shoaling and Breaking of Solitary Waves on Slopes
}

\author{
Rui You, Guanghua He, Yongzhou Cheng, and Xiaoqun Ju
}

\begin{abstract}
Physical experiments were designed and conducted in the water channel to investigate the generation, propagation and shoaling of solitary waves over three different slopes. Firstly, an introduction to the experimental apparatus and the setting of experimental measurement was described. Then, systematic experiments of solitary waves shoaling over slopes were carried out to investigate influences of both the incident wave height and the slope on propagation and shoaling of solitary waves. The incident wave height of solitary waves measured in the present study was $0.06 \mathrm{~m}, 0.09 \mathrm{~m}$ and $0.12 \mathrm{~m}$, and the slope was set with the gradient of 1:10,1:15 and 1:20. Finally, the measured results were analyzed and discussed. The conclusion can be drawn that the maximum run-up of solitary waves and some breaking characteristics are related to the incident wave height and the gradient of the slope.
\end{abstract}

Index Terms - Shoaling, solitary waves, breaking, experiment, propagation.

\section{INTRODUCTION}

Tsunamis are sea surface gravity waves generated by largescale underwater disturbances, such as earthquake. They are commonly referred to as long waves and they are usually modeled by solitary waves in the shallow water. When tsunami wave propagates from abysmal sea to offshore region, because of the decrease in water depth, the wave height increases dramatically and sometimes forms a wall of water before breaking. The run-up, overturn and breaking of solitary waves are the most direct ways to damage the constructions near the offshore. The research on the propagation, shoaling and breaking of tsunami waves is significant to take precaution against natural disaster in offshore engineering.

Tsunami waves are complicated nonlinear waves due to the characteristics of tsunami waves varied as the water depth they propagated varied. So far, it is still a challenge for the present wave theories and numerical models to model the tsunami wave accurately for all regions from the deep sea to shallow sea. The breaking process of tsunami waves are also

Manuscript received November 21, 2016; revised May 21, 2017. This work was supported by Shandong Provincial Natural Science Foundation (ZR2014EEQ016), Open Research Fund Program of Key Laboratory of Water \& Sediment Science and Water Hazard prevention (Changsha University of Science \& Technology), Hunan Province, (2015SS02). Open Research Fund of State Key Laboratory of Satellite Ocean Environment Dynamics (Second Institute of Oceanography, SOA), (SOED1514).

Rui You, Guanghua $\mathrm{He}$ and Xiaoqun Ju are with School of Naval Architecture and Ocean Engineering, Harbin Institute of Technology, Weihai, 264209, China (e-mail: youruiyoyoyo@163.com, ghhe@hitwh.edu.cn, 536758479@qq.com).

Yongzhou Cheng is with Key Laboratory of Water \& Sediment Science and Water Hazard prevention, Changsha University of Science and Technology, Changsha, 410114, China (e-mail:chengyongzhou@163.com). hard to analyze. Thus, physical experiments are utilized by modeling tsunami wave as solitary wave, and shoaling as well as breaking of the waves is measured. The most popular three generation methods of solitary waves both for experimental measurement and numerical simulation are summarized in [1]. There are: (1) a weight fall/slide to a water flume, (2) the flume bottom elevating suddenly, (3) piston-type wavemaker. Ippen and Kulin measured the shoaling and breaking of solitary waves through experiments [2]. Camfield and Street determined criteria for wave growth, celerity, and breaking height on various beach slopes [3]. They pointed out that there was no evidence of breaking for slope angles larger than $12^{\circ}$. $\mathrm{Li}$ and Raichlen [4] conducted an experiment of solitary waves on a 1:15 slope, with relative incident wave height equals to 0.30 and 0.45 , and their results have been validated by the published numerical results. An experiment was carried out to investigate the shoaling characteristics of solitary waves on $1: 35$ and steeper slope $(\geq 1: 6.5)$ by Grilli, Subramanya, Svendsen, and Veeramony [5]. Some scholars and engineers have utilized numerical simulations to analyze the characteristics of solitary waves. Grilli, Svendsen and Subramanya utilized a fully nonlinear potential method to simulate the shoaling and breaking of solitary waves on the slope varies from 1:100 to 1:8 [6]. The run-up of non-breaking and breaking solitary waves on plane impermeable beaches was investigated with a Lagrangian finite-element Boussinesq wave model by Zelt [7]. Wei, Kirby and Grilli computed surface wave propagation in coastal region by using a fully nonlinear Boussinesq model [8]. Some comparisons of numerical, analytical and physical prediction models were made using existing laboratory and field data [9]. Synolakis [10], [11] reviews the numerical model used in tsunami and concludes the state-of-knowledge in tsunami science.

In the present study, a physical experiment is conducted at a water flume. Nine cases of solitary waves shoaling over the slopes with three wave heights and three bottom slopes are carried out. The characteristics of waves during propagation, shoaling and breaking of solitary waves are analyzed and discussed. Based on the measured data from the wave gauges and high-speed video cameras, the effects of both wave height and bottom slope on the shoaling of solitary waves are investigated. The cameras were set in the front of the breaking point, so there will be some error on the solitary profile far away from the breaking point. We neglect the refraction and the partial reflection caused by the glass wall and the bottom of the tank. It is a benefit for a physical insight into complicated wave phenomena of shoaling and breaking of a solitary wave over a mild slope. 


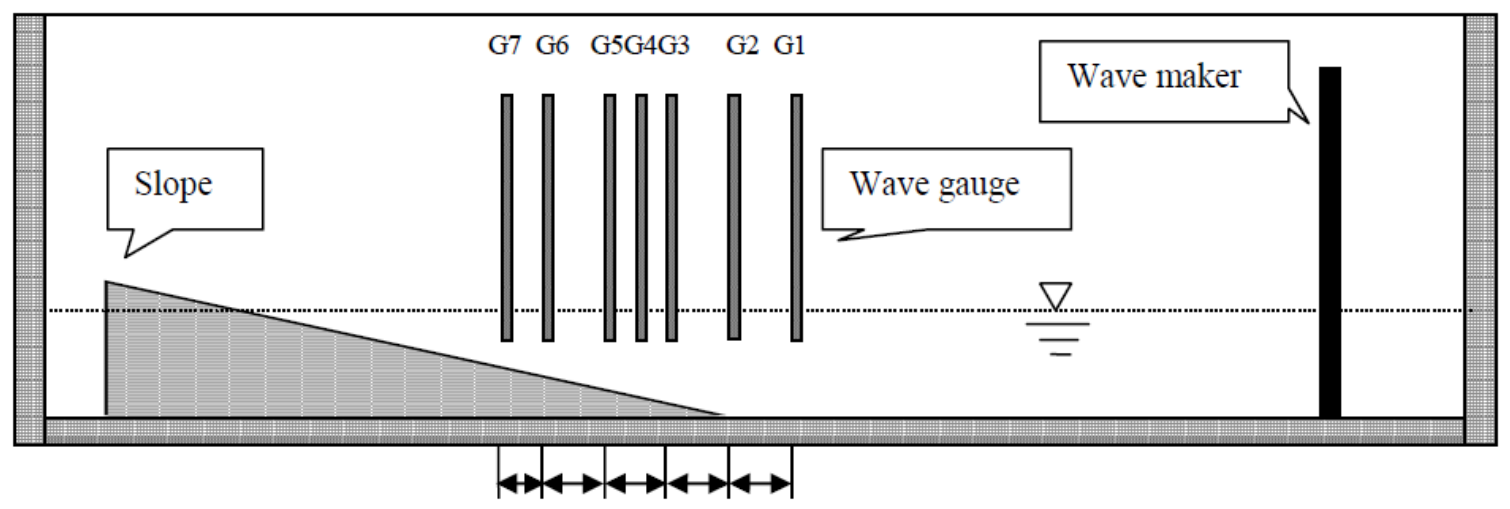

$0.75 \mathrm{~m} 1.5 \mathrm{~m} 1.5 \mathrm{~m} 1.5 \mathrm{~m} 1.5 \mathrm{~m}$

Fig. 1. Layout of experimental model.

\section{LABORATORY EXPERIMENTS}

\section{A. Experimental Model}

As illustrated in Fig. 1, the slope is set at the bottom of the flume to symbolize the beach.

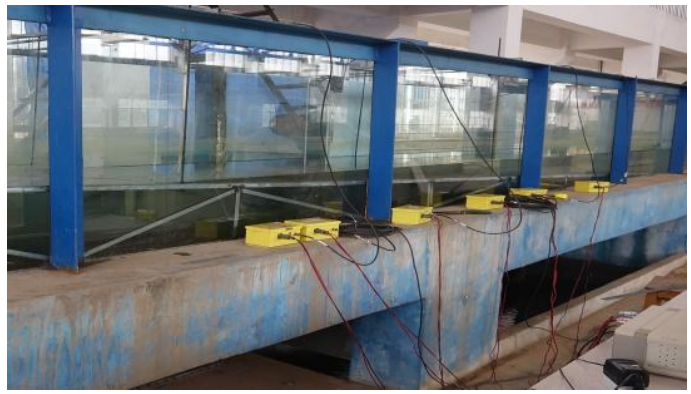

Fig. 2. Flume ready to conduct experiment.

(a)
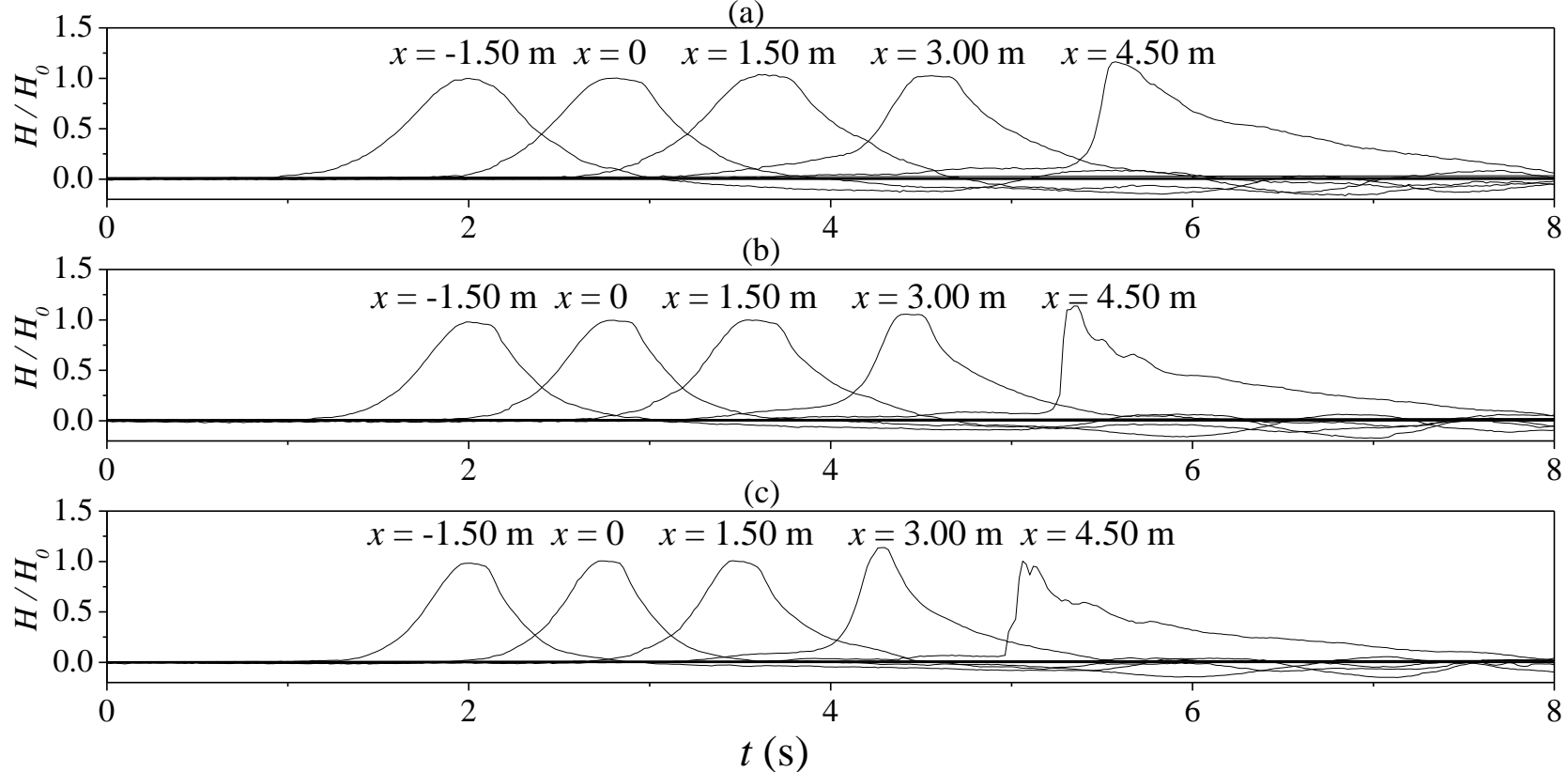

Fig. 3. Time history of solitary waves over a 1:15 slope with $H_{0}$ equals to: (a) $0.06 \mathrm{~m}$; (b) $0.09 \mathrm{~m}$; (c) $0.12 \mathrm{~m}$, measured by wave gauges.

Setting of high-speed video cameras: one with higher resolution is set at $x=3.75$ to capture the phenomenon of wave overturning with its record region from $x=3.0 \mathrm{~m}$ to 4.5 $\mathrm{m}$, and $x$ is the distance away from the toe of the slope. Another is set at $x=5.25 \mathrm{~m}$, to capture the breaking of solitary wave with the record region from $x=4.5 \mathrm{~m}$ to $6.0 \mathrm{~m}$. Six dividing rulers every $1.5 \mathrm{~m}$ of flume width are attached on the glass sidewalls for the convenience of reading and analyzing the elevation of the free surface recorded by the high-speed cameras.

Setting of wave gauges: the first gauge is set at $1.5 \mathrm{~m}$ in front of the slope, which is denoted as $\mathrm{G} 1\left(x_{\mathrm{G} 1}=-1.50 \mathrm{~m}\right)$, and the last gauge is always located close to the expected point of breaking. When the slope is set as 1:10, G1, G2, G3 and G4 have been used and their respective location is $x_{\mathrm{G} 1}=$ $-1.50 \mathrm{~m}, x_{\mathrm{G} 2}=0 \mathrm{~m}, x_{\mathrm{G} 3}=1.50 \mathrm{~m}, x_{\mathrm{G} 4}=2.25 \mathrm{~m}$. For the $1: 15$ slope, $x_{\mathrm{G} 1}=-1.50 \mathrm{~m}, x_{\mathrm{G} 2}=0 \mathrm{~m}, x_{\mathrm{G} 3}=1.50 \mathrm{~m}, x_{\mathrm{G} 5}=3.00 \mathrm{~m}$, $x_{\mathrm{G} 6}=4.50 \mathrm{~m}$. And the locations of wave gauges at 1:20 slope are: $x_{\mathrm{G} 1}=-1.50 \mathrm{~m}, x_{\mathrm{G} 2}=0 \mathrm{~m}, x_{\mathrm{G} 3}=1.50 \mathrm{~m}, x_{\mathrm{G} 5}=3.00 \mathrm{~m}, x_{\mathrm{G} 6}$ $=4.50 \mathrm{~m}, x_{\mathrm{G} 7}=5.25 \mathrm{~m}$.

\section{B. Experimental Equipments}

Experiments were conducted in a wave flume, which is $45.0 \mathrm{~m}$ long, $0.8 \mathrm{~m}$ wide and $1.0 \mathrm{~m}$ deep, in the Laboratory of Port, Coastal and Offshore Engineering, Changsha University of Science \& Technology. As shown in Fig. 2, 
constructed with glass sidewalls throughout and a wavemaker at the end of one side to generate solitary wave, the flume is also equipped with wave damping devices to absorb the reflection of waves. Six wave gauges are set up through the wave flume to measure the elevation of the free surface during the propagation and shoaling of a solitary wave over a slope. Whereas in the breaking and post-breaking regions, the wave profiles are captured by two high-speed video cameras. The pixel of two cameras are 12 million and 14.2 million pixels. The detailed setting of equipment is described in the following section.

\section{Experimental Parameter}

The water depth in the flume was $h_{0}=0.3 \mathrm{~m}$. The slope of the beach with a length of $10.0 \mathrm{~m}$ is adjustable and for these experiments it was set at 1:10, 1:15 and 1:20, respectively with the incident wave height $H_{0}=0.06 \mathrm{~m}, 0.09 \mathrm{~m}, 0.12$ $\mathrm{m}$ (Table I).

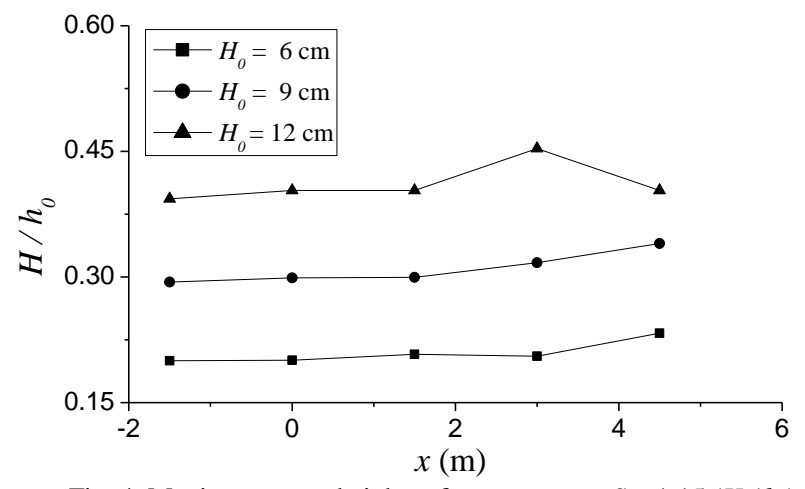

Fig. 4. Maximum wave heights of wave gauges, $S=1: 15\left(H / h_{0}\right)$.

TABLE I: EXPERIMENTAL CASE

\begin{tabular}{llll}
\hline \multicolumn{4}{c}{ TABLE I: EXPERIMENTAL CASE } \\
\hline \hline Water Depth $(\mathrm{m})$ & & 0.3 & \\
\hline Slope & $1: 10$ & $1: 15$ & $1: 20$ \\
Incident Wave Height $(\mathrm{m})$ & 0.06 & 0.09 & 0.12 \\
\hline \hline
\end{tabular}

TABLE II: MaXimum WaVe Heights OF WaVe Gauges

\begin{tabular}{cccc}
\hline \hline$x(\mathrm{~m})$ & Hmax615(cm) & Hmax915(cm) & Hmax1215(cm) \\
\hline-1.50 & $6.00 \mathrm{ta}$ & 8.82 & 11.80 \\
0 & 6.02 & 8.97 & 12.10 \\
1.50 & 6.23 & 8.99 & 12.10 \\
3.00 & 6.16 & 9.51 & 13.60 \\
4.50 & 6.99 & 10.20 & 12.10 \\
\hline \hline
\end{tabular}

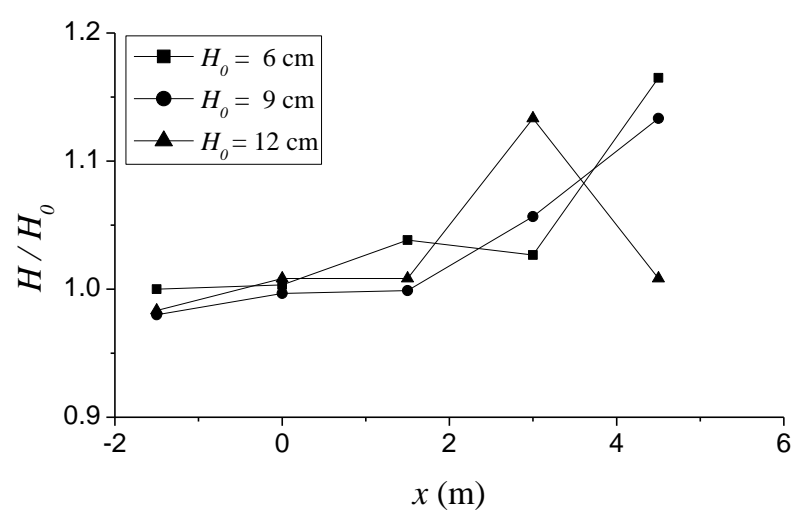

Fig. 5. Maximum wave heights of wave gauges, $S=1: 15\left(H / H_{0}\right)$.

\section{ANALYSIS AS A FUNCTION OF WAVE HEIGHT}

Each experimental case was repeated at least three times and one set of experiments with high degrees of repeatability was chosen as the reliable data for the following analysis. For convenience, we use $\mathrm{H} 610$ to denote the experiment with a $0.06 \mathrm{~m}$ incident wave height over a 1:10 slope. Others are similar with this example. The water surface elevation $H$ is normalized by a factor of $H_{0}$.

\section{A. Shoaling of Solitary Waves}

Fig. 3 shows the shoaling of solitary waves on a slope of $S$ $=1: 15$, with three different incident wave heights $H_{0}=0.06$ $\mathrm{m}, 0.09 \mathrm{~m}$, and $0.12 \mathrm{~m}$. Surface elevations were measured by wave gauges at five different locations over the slope.

In Fig. 3(a), at the location of $1.50 \mathrm{~m}$ away from the toe of the slope $\left(x_{\mathrm{G} 1}=-1.50 \mathrm{~m}\right)$, the shape of solitary waves is symmetric and stable. Wave height stays approximately at $0.06 \mathrm{~m}$, between $x=0 \mathrm{~m}$ and $x=3.00 \mathrm{~m}$, the rise of $H$ is not very apparent. In the distance between $x=3.00 \mathrm{~m}$ and $x=$ $4.50 \mathrm{~m}, H$ has a sharp increase. With increase of the incident wave height $H_{0}=0.09 \mathrm{~m}, H$ surges more dramatically from $x$ $=1.50 \mathrm{~m}$ to $x=4.50 \mathrm{~m}$ than during $x=0 \mathrm{~m}$ and $x=1.50 \mathrm{~m}$, which can be seen from Fig. 3(b). It is obviously seen from the Fig. 3(c) that between $x=1.50 \mathrm{~m}$ and $x=3.00 \mathrm{~m}$, water surface variation has a considerable increase, however, a steep decline happens when propagate to $x=4.50 \mathrm{~m}$.

The figures show that solitary waves have a similar and stable profile for the different incident wave heights before shoaling. The higher the incident wave height, the wider the profile of the solitary wave is. For a given slope, an increase in the speed of propagation occurs as the incident wave height increases. The nonlinearity of solitary wave becomes strong during the wave propagating over a long and mild slope. Solitary waves become asymmetric and their crests steepen while shoaling up the slope. The front of solitary waves becomes steeper, until reaching the breaking point the front of the solitary wave becomes vertical whereas the back is increasingly smoother. Smaller waves have smoother crests and the profile is wider than the bigger ones.

The maximum of wave height measured by wave gauges is summarized in Table II, and the corresponding charts are plotted in Figs. 4 and 5 with the non-dimensional factor different. In Fig. 4, $\mathrm{H}$ is divided by the water depth h0 to get a relative wave height, while in Fig. 5, solitary waves with different incident wave height are divided by their own initial wave height $H_{0}$.

TABLE III: MAXIMUM WAVE HeIGHTS OF WAVE GaUgeS

\begin{tabular}{cccc}
\hline \hline$x(\mathrm{~m})$ & Hmax910(cm) & Hmax915(cm) & Hmax920(cm) \\
\hline-1.50 & 8.78 & 8.82 & 8.97 \\
0 & 9.02 & 8.97 & 9.24 \\
1.50 & 8.97 & 8.99 & 9.20 \\
2.25 & 8.59 & & \\
3.00 & & 9.51 & 9.84 \\
4.50 & & 10.20 & 9.88 \\
5.25 & & & 6.91 \\
\hline \hline
\end{tabular}


(a)
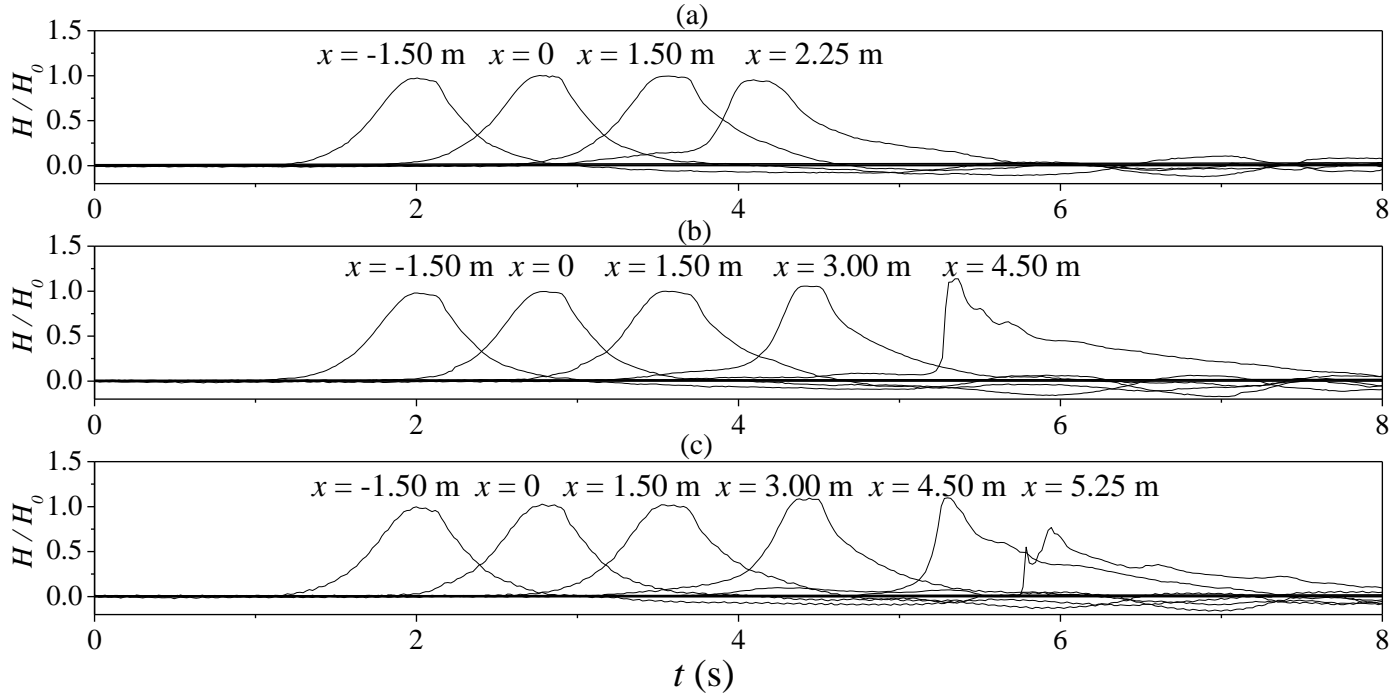

Fig. 6. Time history of solitary waves with $H_{0}=0.09$ m over different slopes: (a) 1:10; (b) 1:15; (c) 1:20, measured by wave gauges.

According to Fig. 4, the maximum of free surface elevation at each gauge in case of H1215 is larger than H915; likewise the elevation in $\mathrm{H} 915$ is bigger than H615, since the nondimensional factor is the water depth $h_{0}$. The conclusion can be drawn that on the same slope, the smaller the incident wave, the smaller the run-up is. In H1215, the elevation of the free surface measured by the wave gauges reached the peak value at $x=3.0 \mathrm{~m}$ then decreased quickly, which indicates the wave breaking occurred in this region. While in cases of H615 and H915, the wave height is still increasing around $x=3$.0. It can be concluded that the breaking of the solitary wave occurs earlier as the incident wave height increased.

It can be seen from Fig. 5, all waves reach the toe of the slope with a slightly larger height. Before the solitary wave reaching the slope, at $x=-1.50$ m both H915 and H1215 have a slight decrease of their initial wave height. H615 keeps a stable wave height for about $1.50 \mathrm{~m}$ until reaching the slope. For cases of H615 and H915, the curve changes mildly before $x=1.50 \mathrm{~m}$, and finally mounts to the maximum point at $x=4.50 \mathrm{~m}$. H1215 stabilizes at the initial wave height before $x=1.50 \mathrm{~m}$, and followed by a considerable increase reaching the peak at $x=3.00 \mathrm{~m}$, then drop down.

\section{B. Breaking of Solitary Waves}

Fig. 4 reveals that the breaking point of H615 and H915 occurs after $x=4.50 \mathrm{~m}$, unlike H1215 breaks between $x=$ $3.00 \mathrm{~m}$ to $x=4.50 \mathrm{~m}$. Though H1215 breaking more rapidly, at $x=4.50 \mathrm{~m}$, the wave height of H1215 is still larger than the smaller waves. After breaking, the wave height plunges dramatically.

\section{ANALYSIS AS FUnCTION OF SLOPE}

Fig. 6 displays the time history of a solitary wave with the incident wave height of $0.09 \mathrm{~m}$ measured by wave gauges at different locations, running up on three different slopes, $S=$ $1: 10,1: 15$, and 1:20. Table III illustrates the maximum wave height measured by each wage gauge, and its corresponding figure is shown in Fig. 7. A dimensionless parameter is obtained by dividing $H_{0}$. Figs. 8-10 are the maximum wave height recorded by two high-speed cameras.

\section{A. Shoaling of Solitary Waves}

As is shown in Fig. 7, before reaching the slope, all the three $H / H_{0}$ have strong similarity in wave profile with a level of the wave height closing to 1.0. This phenomenon verifies the repeatability of the experiments, even in different slopes.

As mentioned in Fig. 3, different incident wave heights cause different propagation velocity of the wave, while Fig. 6 shows that solitary waves over different slopes reach at the same wave gauge almost simultaneously, since the initial solitary waves are the same. So the slope may not influence the solitary wave in terms of velocity a lot, especially for the mild slope in the present study.

During the shoaling, the difference on water surface elevation caused by the slope is not very distinguished before the breaking which can be seen from Fig. 6 at $x=-1.5 \mathrm{~m}, 0 \mathrm{~m}$ and $1.5 \mathrm{~m}$. It also can be confirmed by Fig. 7, $H$ is similar with each other before $x=1.5 \mathrm{~m}$. After $x=1.5 \mathrm{~m}$, the apparent difference between the cases of different slopes can be found in Fig. 6. On the steepest 1:10 slope, solitary wave breaks between $x=1.50 \mathrm{~m}$ to $x=2.25 \mathrm{~m}$, and the breaking point of H915 occurs roughly at $x=4.50 \mathrm{~m}$, whereas H920 breaks after $x=4.50 \mathrm{~m}$. On the gentle slope, solitary wave would propagate for long distances before breaking.

For further investigating the characteristics of the solitary wave near the breaking point, Figs. 8-10 show the maximum wave height before the breaking point recorded by the video cameras. To show the profile clearly, we deepen the water surface. By reading the maximum wave height according to the ruler attached on the glass wall, table IV is summarized.

It can be seen that at the breaking point, the front of the wave has a vertical tangent and video data have the accordance with the data measured by wave gauges. Maximum height acquired by the video cameras (Table IV) exceeds the dada measured by wave gauges (Table III) since the wave gauge is not located at the actual breaking point.

\section{B. Breaking of Solitary Waves}

At the breaking point, Fig. 6(a) has the broader profile of solitary wave than Fig. 6(c). This indicates that a significant decrease in the intensity of breaking takes place when the slope becomes gentler. 
The breaking procedure of these experiments seems distinguished with each other. Over the steepest slope, solitary wave height decreases slightly after breaking. However, in H920, $H$ jumps heavily after breaking point. On a gentle slope, in the post breaking region, the wave height decreases drastically over a short distance.

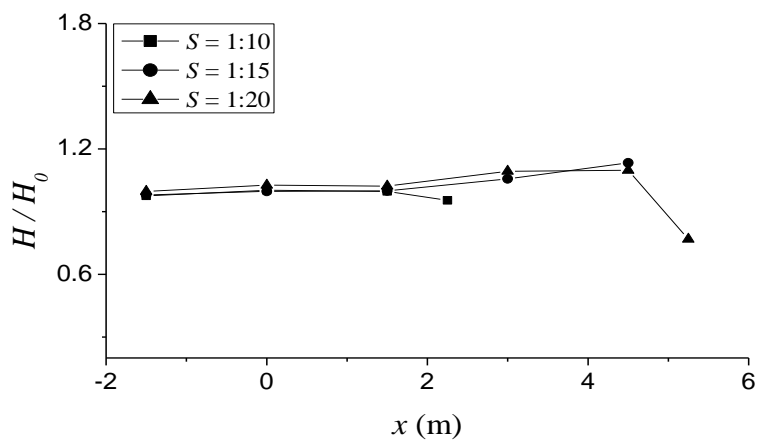

Fig. 7. Maximum wave heights of wave gauges, $H_{0}=9 \mathrm{~cm}$.

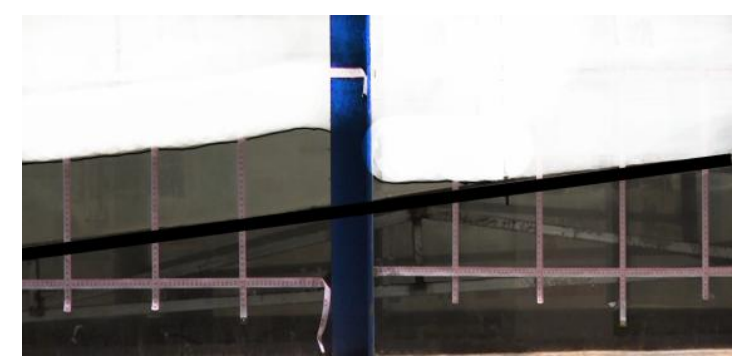

Fig. 8. Maximum wave height of H910.

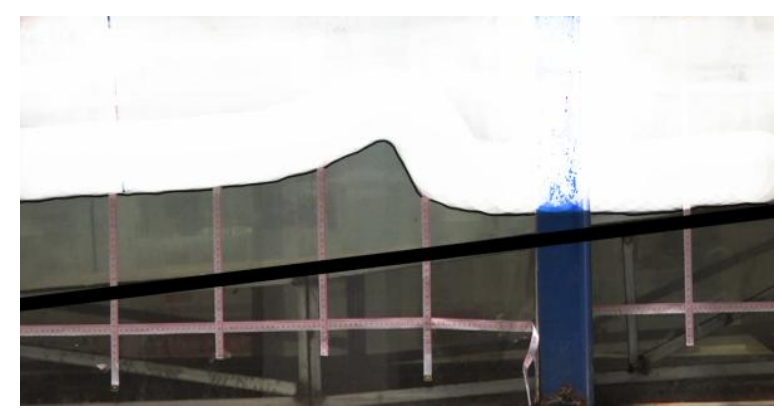

Fig. 9. Maximum wave height of H915.

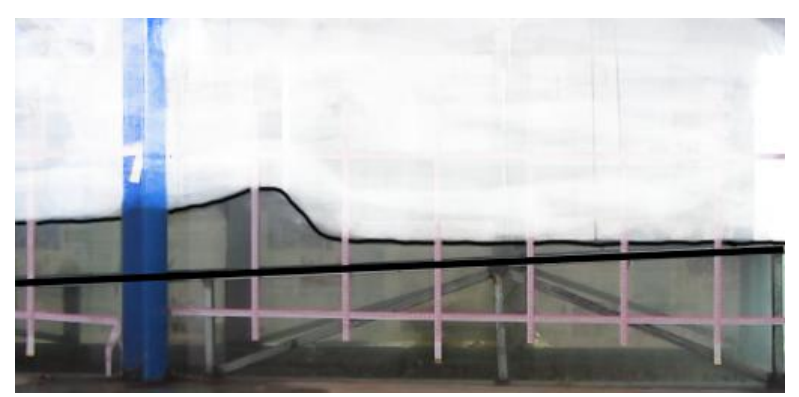

Fig. 10. Maximum wave height of H920.

TABLE IV: MAXIMUM WAVE HEIGHT AND ITS LOCATION, RECORDED BY

\begin{tabular}{cccc} 
& \multicolumn{3}{c}{ CAMERAS } \\
\hline \hline$x(\mathrm{~m})$ & $\mathrm{H} 910$ & $\mathrm{H} 915$ & H920 \\
\hline $\operatorname{Hmax}(\mathrm{cm})$ & 2.9 & 4.1 & 4.9 \\
& 12.0 & 12.0 & 13.0 \\
\hline \hline
\end{tabular}

\section{CONCLUSION}

Physical experiments were conducted in the water channel to investigate the generation, propagation and shoaling of solitary waves over slopes. Three wave heights of $H_{0}=0.06$ $\mathrm{m}, 0.09 \mathrm{~m}, 0.12 \mathrm{~m}$ and three slopes of $1: 10,1: 15$ and 1:20 were involved. The effects of both the incident wave height and the slope on offshore propagation and shoaling of solitary waves were investigated. The conclusion can be drawn that on the same slope, the run-up of solitary waves goes up and the breaking point occurs early as the incident wave height increased. For the same incident wave height, as the gradient of the slope decrease, the solitary wave propagates for a longer distance before breaking, and also a decrease in the intensity of breaking takes place.

\section{ACKNOWLEDGMENT}

The authors would like to express their gratitude to members of Yongzhou Cheng's Research Group, Changsha University of Science \& Technology, for their support in both labor force and an experimental facility.

Thanks for the graduate Chengzhi Gao, from Harbin Institute of Technology, Weihai, his participation in the experiment helps a lot.

\section{REFERENCES}

[1] G. He and M. Kashiwagi, "Numerical analysis of the hydroelastic behavior of a vertical plate due to solitary waves," Journal of Marine Science and Technology, vol. 17, no. 2, pp. 154-167, 2012.

[2] A. T. Ippen and G. Kulin, "The shoaling and breaking of the solitary wave," Coastal Engineering Proceedings, vol. 1, no. 5, pp. 27-49, 1954.

[3] F. E. Camfield and R. L. Street, "Shoaling of solitary waves on small slopes," Journal of the Waterways and Harbors Division, vol. 95, no. 1 , pp. 1-22, 1969.

[4] Y. Li and F. Raichlen, "Discussion of "Breaking Criterion and characteristics for solitary waves on slopes" by Ying Li and Fredric Raichlen," American Society of Civil Engineers, no. 6, pp. 329-335, 1998.

[5] S. T. Grilli, R. Subramanya, I. A. Svendsen, and J. Veeramony, "Shoaling of solitary waves on plane beaches," Journal of Waterway Port Coastal \& Ocean Engineering, vol. 120, no. 6, pp. 609-628. 1994.

[6] S. T. Grilli, I. A. Svendsen, and R. Subramanya, "Breaking Criterion and Characteristics for Solitary Waves on Slopes," Macromolecular Bioscience, vol. 4, no. 3, pp. 340-345. 1997.

[7] J. A. Zelt, "The run-up of nonbreaking and breaking solitary waves," Coastal Engineering, vol. 15, no. 3, pp. 205-246, 1991.

[8] G. Wei, J. T. Kirby, and S. T. Grilli, "A fully nonlinear Boussinesq model for surface waves. Part 1 . Highly nonlinear unsteady waves," Journal of Fluid Mechanics, vol. 294, no. 1, pp. 71-92, 1995.

[9] H. H. J. Yeh, C. Synolakis, and P. L. F. Liu, "Long-wave runup models: Friday harbor," USA: World Scientific, pp. 12-17, 1995.

[10] C. E. Synolakis and E. N. Bernard, "Tsunami science before and beyond boxing day 2004," Philosophical Transactions of the Royal Society A Mathematical, vol. 364, no. 1845, pp. 2231-65, 2006.

[11] C. E. Synolakis, E. N. Bernard, V. V. Titov, U. Kânoğ lu, and F. I. González, "Validation and verification of tsunami numerical models," Pure and Applied Geophysics, vol. 165, no. 11, pp. 2197-2228, 2008.

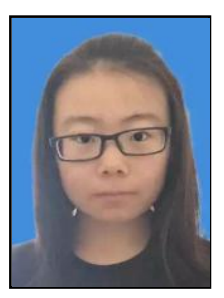

Rui You was born in Shandong province, China, in 1996. She is a senior student, majoring in naval architecture and ocean engineering. And will earn her bachelor's degree in 2017 in naval architecture and ocean engineering, Harbin Institute of Technology, Weihai, China.

She doesn't have a job yet. She would like to devote herself into hydrodynamics.

professional societies. 


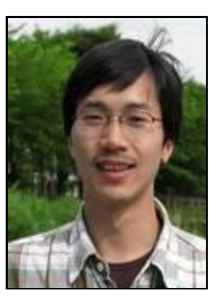

Guanghua He was born in Zhejiang province, China, 1980. He received his bachelor of port coastal and offshore engineering from Tianjin University from 1999 to 2003; He received his bachelor of computer science and technology (the second degree) from Tianjin University from 1999 to 2003; He received his master of port, coastal and offshore engineering from Dalian University of Technology from 2003 to 2006; He received his doctor degree in marine atmospheric environment engineering from Kyushu University, Institute for Applied Mechanics from 2006 to 2009.

He started his career in 2009. His work experience is as follows: 2009.11-2014.03 Osaka university, assistant professor of ship and ocean engineering. From 2014.05 until now, School of Naval Architecture and Ocean Engineering, Harbin institute of technology, weihai, professor, doctoral tutor. His research interests are strongly nonlinear ship motion and hydrodynamic problems, the ship's seakeeping and wave load, the fluid-solid coupling water elastic analysis, marine hydraulic engineering.

Prof. He is the member of International Society of Ocean and Polar Engineering.

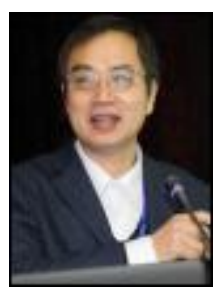

Yongzhou Cheng was born in Hubei province, China. He received his doctor of port, coastal and offshore engineering from Dalian Institute of Technology from 2002 to 2007; He received his master of river-and-harbor engineering from Changsha Traffic Institute (now Changsha University of Science and Technology from 1999 to 2002.
He started his career in 2007, His worked as a associate professor at the Changsha University of Science and Technology, Water Conservancy Engineering College from 2007/11 to 2010.11; His worked as a professor at the University of Western Australia, Department of Civil and Resources Institute, Visiting Scholar from 2010/10 to 2011.10. From 2010.11 until now, Changsha University of Science and Technology, Water Conservancy Engineering College,. His research interests are River coast dynamics and sediment movement; Wave and seabed - structure interaction

Prof. Cheng professional committee of the sixth China water conservancy institute of water conservancy measurement technology and editorial board member of Marine Engineering.

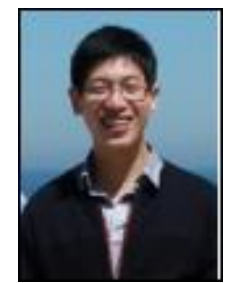

Xiaoqun Ju was born in China. He received his bachelor of turbine thermal power engineering from Dalian Maritime University from 2006 to 2010; He received his master of marine engineering from Dalian Maritime University from 2010 to 2012.

He started his career from 2014.05 until now, is a School of Naval Architecture and Ocean Engineering, Harbin Institute of Technology, Weihai. His research interests are overall design of ship and Marine structures, manufacturing process design, structure design. 